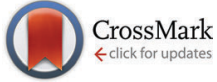

Cite this: Phys. Chem. Chem. Phys., 2016, 18, 27738

Received 20th June 2016

Accepted 9th September 2016

DOI: $10.1039 / c 6 c p 04298 h$

www.rsc.org/pccp

\title{
Ligand effects on the optical and chiroptical properties of the thiolated $\mathrm{Au}_{18}$ cluster $\dagger$
}

\author{
Alfredo Tlahuice-Flores
}

The effect of chiral and achiral ligands protecting the inner $\mathrm{Au}_{9}$ core of the $\mathrm{Au}_{18}(\mathrm{SR})_{14}$ cluster is studied based on density functional theory (DFT) and its corrected long-range interaction (DFT-D) approach. It was found that the electronic properties (energy levels) depend on the specific ligands, which induce distinct distortions on the Au-S framework. However, the substitution of $\mathrm{S}-\mathrm{c}-\mathrm{C}_{6} \mathrm{H}_{11}$ as $\mathrm{SCH}_{3}$ ligands may be considered to be correct given the obtained resemblance to the displayed bonding, optical and chiroptical properties. A further comparison of the $C D$ and $U V$ spectra displayed by the $\mathrm{Au}_{18}$ cluster protected by chiral and achiral ligands attests that more intense profiles are featured by ligands including phenyl rings and/or oxygen atoms such that the $\mathrm{Au}_{18}$ cluster protected by either achiral metamercaptobenzoic acid $(m-M B A)$ or achiral SPh ligands displays more intense UV and CD signals. These results provide new insight into the effect of ligands on thiolated gold clusters.

In 2015 , the structure of thiolated $\mathrm{Au}_{18}$ cluster protected by S-c-C $\mathrm{C}_{6} \mathrm{H}_{11}$ ligands was solved by means of X-Ray diffractions studies but its CD spectrum was missed. ${ }^{1}$

In contrast, previous theoretical models ${ }^{2}$ and experimental reports had established the $\mathrm{Au}_{18}$ cluster to be chiral whereby its CD spectra were known. ${ }^{3}$ In the experimental report of the $\mathrm{Au}_{18}(\mathrm{SR})_{14}$ cluster the lack of a CD signal was attributed to the presence of a symmetry plane. However, in a recent computational study, the $C_{1}$ symmetry was preferred over the $C_{\mathrm{s}}$ symmetry by circa $3.0 \mathrm{eV} .^{4}$ This result supports the hypotheses that the $\mathrm{Au}_{9}$ inner core is intrinsically chiral while the cyclohexyl $\left(\mathrm{S}-c-\mathrm{C}_{6} \mathrm{H}_{11}\right)$ ligand is achiral.

In this communication a systematic study of the influence of chiral and achiral ligands on the structural, optical and chiroptical properties of the thiolated $\mathrm{Au}_{18}$ cluster has been conducted. The importance of this study lies in the photochemical

CICFIM-Facultad de Ciencias Físico-Matemáticas, Universidad Autónoma de Nuevo León, San Nicolás de los Garza, NL 66450, Mexico. E-mail: tlahuicef@gmail.com $\dagger$ Electronic supplementary information (ESI) available: A full bond length graph of all structures, a comparison of their gold cores, and the contribution to energy levels of atoms are provided. See DOI: 10.1039/c6cp04298h properties of the $\mathrm{Au}_{18}$ cluster and in its potential applications. ${ }^{5}$ Two sets of ligands were selected: one set comprised eight achiral ligands and a second set, three chiral ligands. All calculations are based on density functional theory (DFT) ${ }^{6}$ and/or its corrected long-range interaction (DFT-D) ${ }^{7}$ approach. It is important to mention that the consideration of long-range forces (van der Waals interactions) is important when the organic part of the ligand is constituted by chemical groups that are expected to interact among themselves (interligand interaction) and with the environment. The ligand effects on the structure of thiolated $\mathrm{Au}_{15}$ cluster was reported in 2013, and the consideration of the $N$-acetyl-L-cysteine (NAC) as a ligand resulted in a lower energy isomer. ${ }^{8}$ Moreover, the effect of ligands on the optical properties of various protected gold clusters has been found or computationally predicted, for example, into the thiolated $\mathrm{Au}_{25}$ cluster the ligands effect was revealed as a distortion into the $\mathrm{Au}-\mathrm{S}$ framework, ${ }^{9}$ and on the structure of the $\mathrm{Au}_{24}$ cluster where thiolate or selenolate ligands organized forming various kind of motifs. ${ }^{10}$ In thiolated $\mathrm{Au}_{40}$ clusters a major dependency on the ligand type was reported; a 2-phenylethylthiolate (2-PET) ligand conduced to a structure with an oblate $\mathrm{Au}_{26}$ core, ${ }^{11}$ while a 2-methylbenzenethiolate ligand produced a snowflake-like $\mathrm{Au}_{25}$ core (determined experimentally). ${ }^{12}$

The idea of an intact core can be exemplified by the thiolated $\mathrm{Au}_{36}$ cluster which has been synthesized using three different types of ligands ( $\mathrm{SPh}, \mathrm{SPh}-t-\mathrm{Bu}$ and $\left.\mathrm{SC}_{5} \mathrm{H}_{9}\right) .{ }^{13}$ This result was unexpected because those ligands are very different; the $S P h-t-B u$ (or TBBT) ligand due to its bulkiness might induce distortions into the Au-S framework, while in the SPh ligand the induced distortion might be due to its aromaticity. The cyclopentylthiolate $\left(\mathrm{SC}_{5} \mathrm{H}_{9}\right)$ ligand, being nonaromatic, could have a moderate influence on the structural properties, but based on its steric hindrance, it imposes the largest steric stress. ${ }^{13 c}$ It was thought that the influence of ligands was due to steric effect or derived from the aromaticity (aromatic thiols) and electronic effects. However, it is necessary to consider the interaction between gold core atoms and ligands or between ligands constituted by active chemical groups. In this study, van der Waals interactions were 
included by using the method of Grimme et al..$^{7}$ Moreover, generalized gradient approximation (GGA $)^{14}$ and the PerdewBurke-Ernzerhof (PBE) exchange-correlation functional was used. ${ }^{15}$ The LANL2DZ basis set was employed for Au atoms (19 valence electrons) and the $6-31 \mathrm{G}(\mathrm{d}, \mathrm{p})$ basis set for $\mathrm{H}, \mathrm{S}, \mathrm{C}, \mathrm{N}$, and $\mathrm{O}$ atoms. The structural optimizations were performed using a force tolerance criterion of $0.01 \mathrm{eV} \AA^{-1}$. All mentioned methodologies were implemented using the Gaussian 09 (G09) package. ${ }^{16}$ The mentioned DFT-PBE methodology, with no consideration of the long-range interactions, has been amply used by the author in the study of thiolated gold clusters, and finds good agreement with the experiments and other calculations. ${ }^{8,9,17}$

A set of eleven ligands, included in experimental or theoretical reports devoted to the study of thiolated gold clusters, is considered along this study. The first set of eight achiral ligands includes para-mercaptobenzoic acid $(p$-MBA $),{ }^{18} \quad \mathrm{SPh},{ }^{19,20}$ $\mathrm{SPhNO}_{2},{ }^{21}$ cyclohexanethiol $\left(\mathrm{S}-c-\mathrm{C}_{6} \mathrm{H}_{11}\right),{ }^{1,22,23}$ 2-phenylethylthiolate (2-PET) ${ }^{24}$ mercaptopropionic acid (MPA that has been considered in gold nanoparticles), ${ }^{25}$ besides the amply used $\mathrm{SCH}_{3}$ ligand during calculations. Starting from the experimental $\mathrm{Au}_{18}$ cluster protected by $14 \mathrm{~S}-c-\mathrm{C}_{6} \mathrm{H}_{11}$ ligands, a set of initial structures was built; some of them are depicted in Fig. 1-5. After relaxation, calculations based on a DFT-D approach show ligands with different orientations with respect to the DFT relaxed ones (Fig. 1, 3 and 4). This distinct orientation was expected to affect both the $\mathrm{Au}-\mathrm{S}$ framework of the studied clusters and their electronic properties. Interestingly, clusters protected
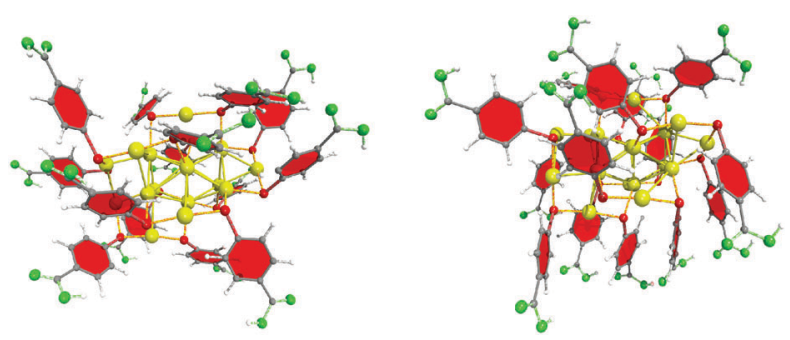

Fig. 1 Structure of the optimized $\mathrm{Au}_{18}$ cluster protected with achiral p-MBA ligands. $\mathrm{Au}, \mathrm{S}, \mathrm{C}, \mathrm{O}$, and $\mathrm{H}$ atoms are shown in yellow, red, gray, green, and white, respectively. It is evident that by including the long-range interactions (right panel), phenyl rings orientate allowing $\mathrm{COOH}$ groups to interact forming ordered patterns (bottom of the right panel).
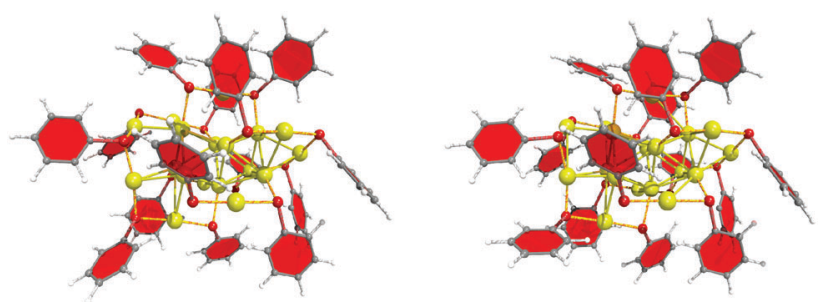

Fig. 2 Structure of the optimized $\mathrm{Au}_{18}$ cluster protected with SPh ligands. There is no clear difference on the orientation of the phenyl rings (depicted in red) after considering the long-range interactions (right panel). The cause of the small interaction between phenyl rings might be ascribed to the large space on the gold core.
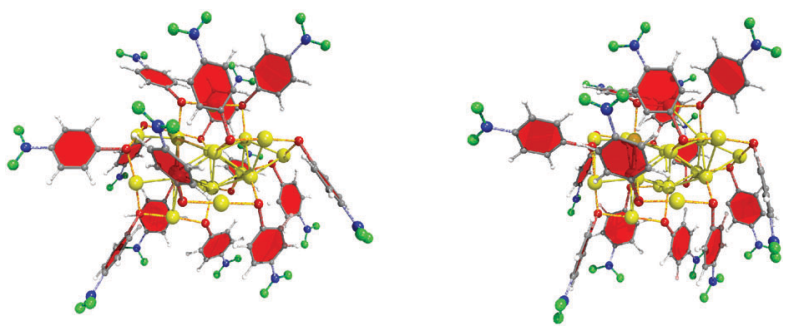

Fig. 3 Structure of the optimized $\mathrm{Au}_{18}$ cluster protected with $\mathrm{SPhNO}_{2}$ ligands. $\mathrm{N}$ atoms are shown in blue. The DFT-D (right panel) structure displays a major interaction between near NO groups shifting the orientation of phenyl rings.
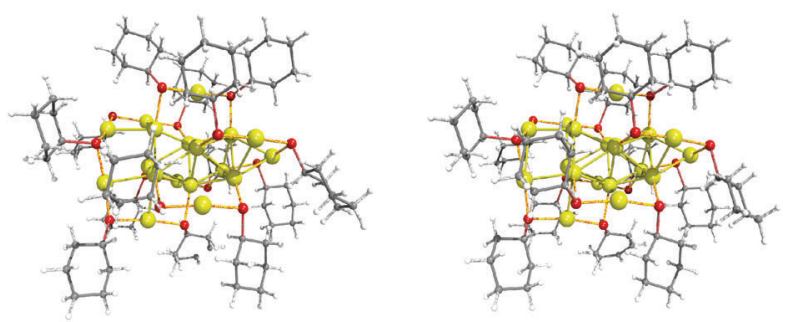

Fig. 4 Structure of the optimized $A u_{18}$ cluster protected with $\mathrm{S}-\mathrm{c}-\mathrm{C}_{6} \mathrm{H}_{11}$ ligands. Both structures are closely related with no influence of the van der Waals interactions (right panel).
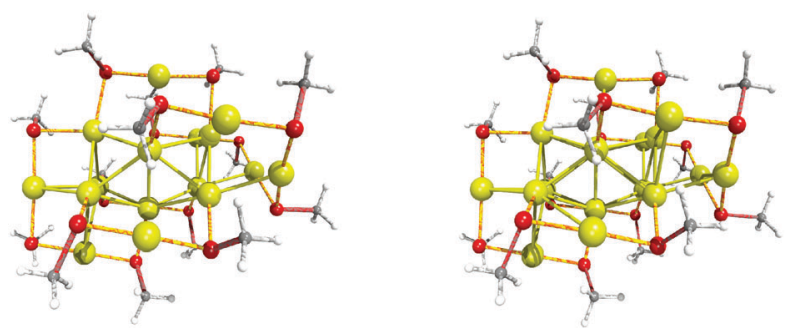

Fig. 5 Structure of the optimized $\mathrm{Au}_{18}$ cluster protected with $\mathrm{SCH}_{3}$ ligands. Both structures are closely related with no influence of the correction of the long-range interactions (right panel), and the core and $\mathrm{Au}-\mathrm{S}$ framework seems to remain intact.

by SPh (Fig. 2), S-c- $\mathrm{C}_{6} \mathrm{H}_{11}$ (Fig. 4), and $\mathrm{SCH}_{3}$ ligands (Fig. 5) show a similar Au-S framework. This similarity is found even in structures relaxed by means of DFT-D calculations (see Fig. S1-S5, $\mathrm{ESI} \dagger$ ). Hence, the well-known interaction between phenyl rings ${ }^{23}$ is diminished even in the $\mathrm{Au}_{18}$ cluster protected with SPh ligands, which must be ascribed to the space available on the surface of the gold core that might reduce the steric hindrance. Up to now it is important to note how S-c- $\mathrm{C}_{6} \mathrm{H}_{11}, \mathrm{SPh}$ and $\mathrm{CH}_{3}$ ligands seem to maintain the $\mathrm{Au}_{9}$ core intact.

A further bonding analysis revealed a stronger distortion into the Au-S framework (Fig. S6, ESI $\dagger$, left panel) of the DFT relaxed $\mathrm{Au}_{18}$ cluster including $p$-MBA ligands, and this result is in accordance with an early study devoted to the thiolated $\mathrm{Au}_{25}$ cluster. ${ }^{9}$ However, the DFT-D optimized structure features distinct $\mathrm{Au}$ bond lengths in the core $\left(\mathrm{Au}_{\mathrm{c}}-\mathrm{Au}_{\mathrm{c}}\right.$ bonds) from those involving core and staples $\left(\mathrm{Au}_{\mathrm{c}}-\mathrm{Au}_{\mathrm{s}}\right)$. Additionally, less dispersed $\mathrm{Au}_{\mathrm{c}}-\mathrm{Au}_{\mathrm{c}}$ bonds are found with respect to DFT relaxed 


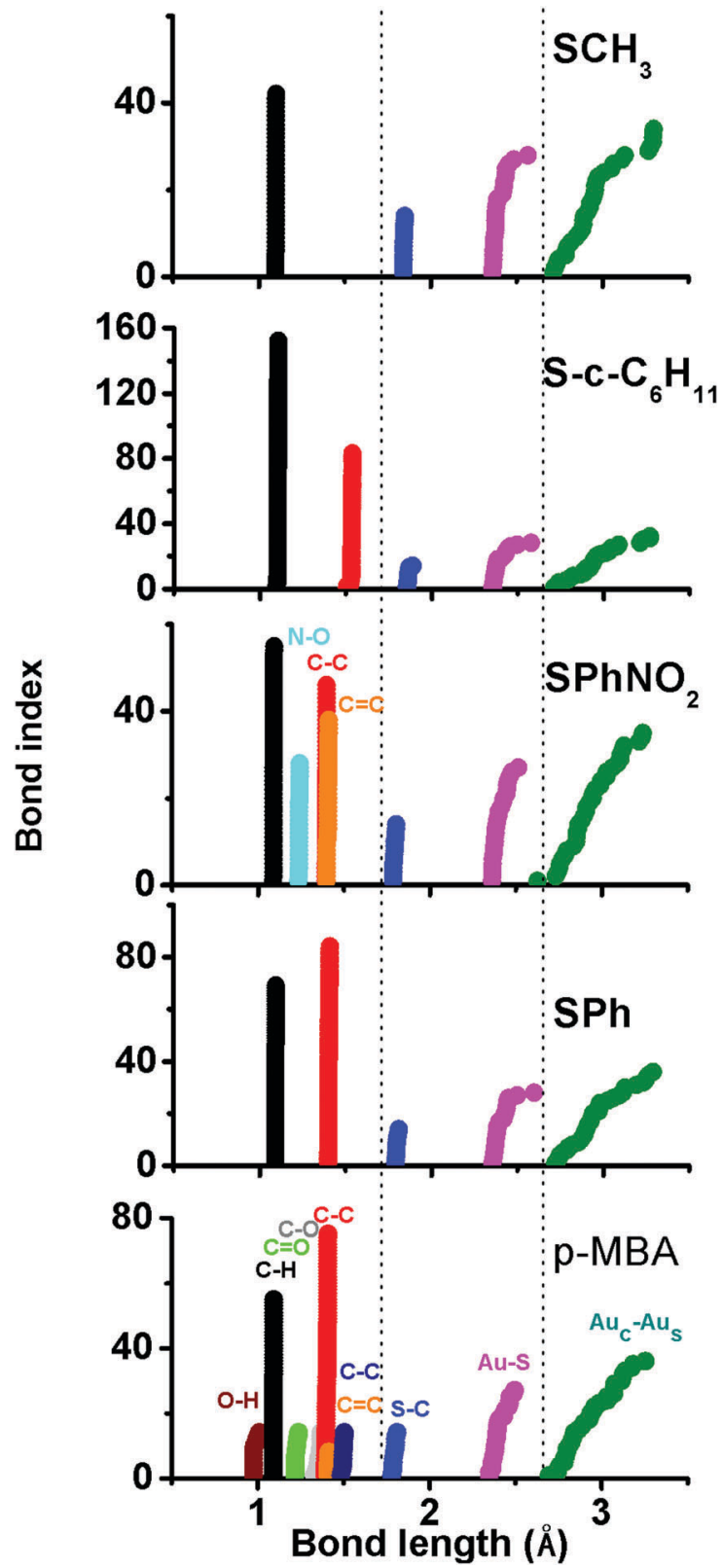

Fig. 6 Bond lengths of relaxed thiolated $\mathrm{Au}_{18}$ structures based on DFT-D calculations. Coloured labels are used to identify bonds present in each compound. $\mathrm{Au}_{18}$ clusters protected with $p-\mathrm{MBA}, \mathrm{SPh}$ and $\mathrm{SPhNO}_{2}$ depict short $\mathrm{S}-\mathrm{C}$ bonds.

structures. This result may be due to the interligand interaction between carboxyl groups, which results in a compact gold core, with less dispersed $\mathrm{Au}-\mathrm{S}$ bonds, while the $\mathrm{S}-\mathrm{C}$ bond lengths are reduced slightly. The borderline between both $\mathrm{Au}-\mathrm{S}$ and $\mathrm{Au}-\mathrm{Au}$ bonds displayed by all studied clusters is indicated by a dotted line in Fig. 6, and a complete comparison of the bonding types displayed by DFT and DFT-D structures is shown in Fig. S6 (ESI $\dagger$ ). This result demonstrates that the effect of the ligands cannot be ascribed merely to their bulkiness but to the presence of chemical groups and to their interaction. Chiral ligands were considered in addition and their structures are provided (see Fig. S7, ESI $\dagger$, for optimized structures).
From Fig. 7, it is evident that $\mathrm{NH}_{2}$ groups substituted in 2-PET produce a distortion of $\mathrm{C}-\mathrm{C}, \mathrm{S}-\mathrm{C}$, and $\mathrm{Au}-\mathrm{S}$ bonds. However, clusters protected by 2 -PET and $\mathrm{S}-\mathrm{CH}_{2}-\mathrm{CH}\left(\mathrm{CH}_{3}\right)-\mathrm{Ph}$ (2-PET-Met)

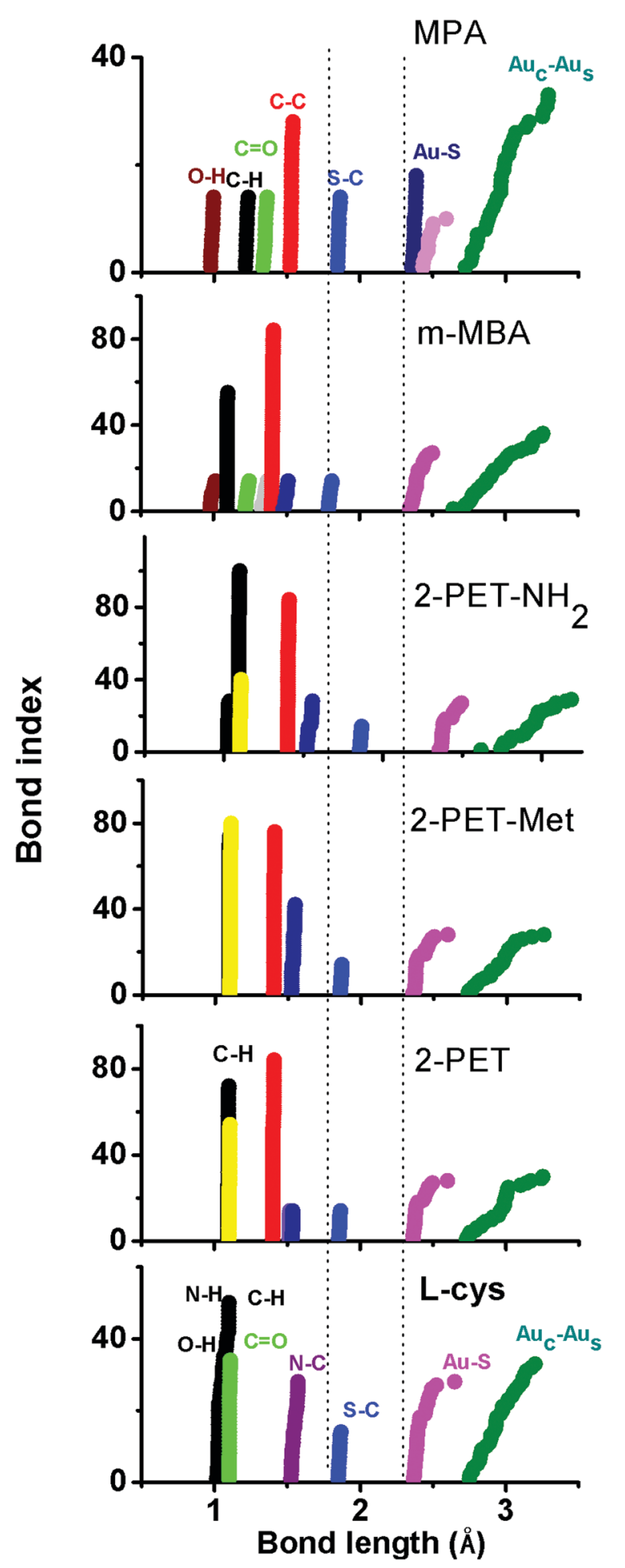

Fig. 7 Bond lengths of relaxed thiolated $\mathrm{Au}_{18}$ structures based on DFT calculations. Bond types are identified by labels. $\mathrm{Au}_{18}$ clusters protected with achiral $m-M B A$ and chiral $L-c y s t e i n e$ depict short $\mathrm{S}-\mathrm{C}$ bonds. Interestingly $\mathrm{Au}_{18}$ protected with L-cysteine shows similar $\mathrm{N}-\mathrm{H}, \mathrm{O}-\mathrm{H}$ and $\mathrm{C}-\mathrm{H}$ bonds. Moreover, it is evident that major distortion is induced by L-cysteine and MPA ligands. 
ligands are similar. ${ }^{26}$ Meanwhile those structures protected by $\mathrm{SCH}_{3}, \mathrm{SPh}$, and S- $c-\mathrm{C}_{6} \mathrm{H}_{11}$ seem to maintain an "intact" $\mathrm{Au}_{9}$ core. A comparison of the inner cores of relaxed structures revealed as the main difference some deflections induced into the tetramer motif (Fig. S1 and S3, ESI $\dagger$ ). Once again, $\mathrm{SCH}_{3}, \mathrm{SPh}$, and $\mathrm{S}-c-\mathrm{C}_{6} \mathrm{H}_{11}$ ligands do not interact strongly, in such manner that the DFT and DFT-D relaxed structures look quite similar.

Up to now the influence of the ligands on the bonding displayed by the studied structures is evident, and it was expected that related optical absorption (UV) and circular dichroism (CD) spectra also showed a ligand dependency.

The obtained optical absorption and CD spectra profiles of the set comprised of achiral ligands, based on both DFT (black curves) and DFT-D calculations, are shown in Fig. 8. The calculated profiles of clusters protected by $\mathrm{SCH}_{3}, \mathrm{SPh}$ and S- $c-\mathrm{C}_{6} \mathrm{H}_{11}$ are similar independent of whether or not long range interactions are taken into consideration. This supports the idea that when there are no active chemical groups included in the ligands, then both types of calculations converge to similar curves. It needs to be remembered that the experimentally determined structure of $\mathrm{Au}_{18}(\mathrm{SR})_{14}$ clusters was protected by achiral S- $c-\mathrm{C}_{6} \mathrm{H}_{11}$ ligands and calculations show similar UV and CD spectra of clusters protected by both ligands and therefore the $\mathrm{S}-c-\mathrm{C}_{6} \mathrm{H}_{11}$ ligand can be substituted by $\mathrm{SCH}_{3}$ ligands during calculations. It is worth noting the better agreement in the relative intensity of the first two peaks shown on the $\mathrm{Au}_{18}$ cluster protected by $\mathrm{S}-c-\mathrm{C}_{6} \mathrm{H}_{11}$ ligands when compared with the experimental spectrum (Fig. S8, ESI $\dagger$ ). The importance of including van der Waals interactions is shown in Fig. S9 (ESI $\dagger$ ), where a slightly better agreement in the position of UV peaks with the experiment is obtained. Another interesting fact is that the $\mathrm{CD}$ curve is less intense for the cluster protected by $\mathrm{S}-c-\mathrm{C}_{6} \mathrm{H}_{11}$ ligands than for clusters protected by $\mathrm{SPh}, \mathrm{SPhNO}_{2}$ and $p$-MBA ligands. Our study demonstrates that the $\mathrm{Au}_{18}(\mathrm{SR})_{14}$ cluster protected by $\mathrm{S}-c-\mathrm{C}_{6} \mathrm{H}_{11}$ ligands shows a weak $\mathrm{CD}$ signal.

In order to know how the contribution of achiral ligands influences the electronic structure of related $\mathrm{Au}_{18}(\mathrm{SR})_{14}$ clusters, their contribution to the energy levels was determined. The energy level diagrams are included in Fig. S10 (ESI $\dagger$ ) and they reveal that the oxygen atoms, in the cluster protected by $p$-MBA, make an important contribution to the HOMO level. Clearly, the DFT calculations, where carboxyl and hydroxyl groups do not interact and therefore do not form patterns, show a major contribution to the HOMO level coming from the oxygen atoms. This result is important because it supports the idea that it is not necessary that the first peak must be associated uniquely with metal-centered transitions because ligands are able to modulate the electronic structure of thiolated gold clusters. For example, the first weak peak (small oscillator strength) located at $1.33 \mathrm{eV}$ is mainly associated with a HOMO $\rightarrow$ LUMO (96\%) transition. Another peak located at $1.92 \mathrm{eV}$ (red curve in Fig. 8) has contributions mainly from $\mathrm{H}-13 \rightarrow$ LUMO (75\%) and $\mathrm{H}-12 \rightarrow$ LUMO (7\%) electronic transitions that involve energy levels with a high contribution from oxygen atoms (the $\mathrm{H}-12$ level holds a contribution of $25 \%$ coming from $\mathrm{O}$ atoms). Interestingly, the $\mathrm{Au}_{18}$ cluster protected by $p$-MBA and relaxed by means of DFT shows a HOMO level
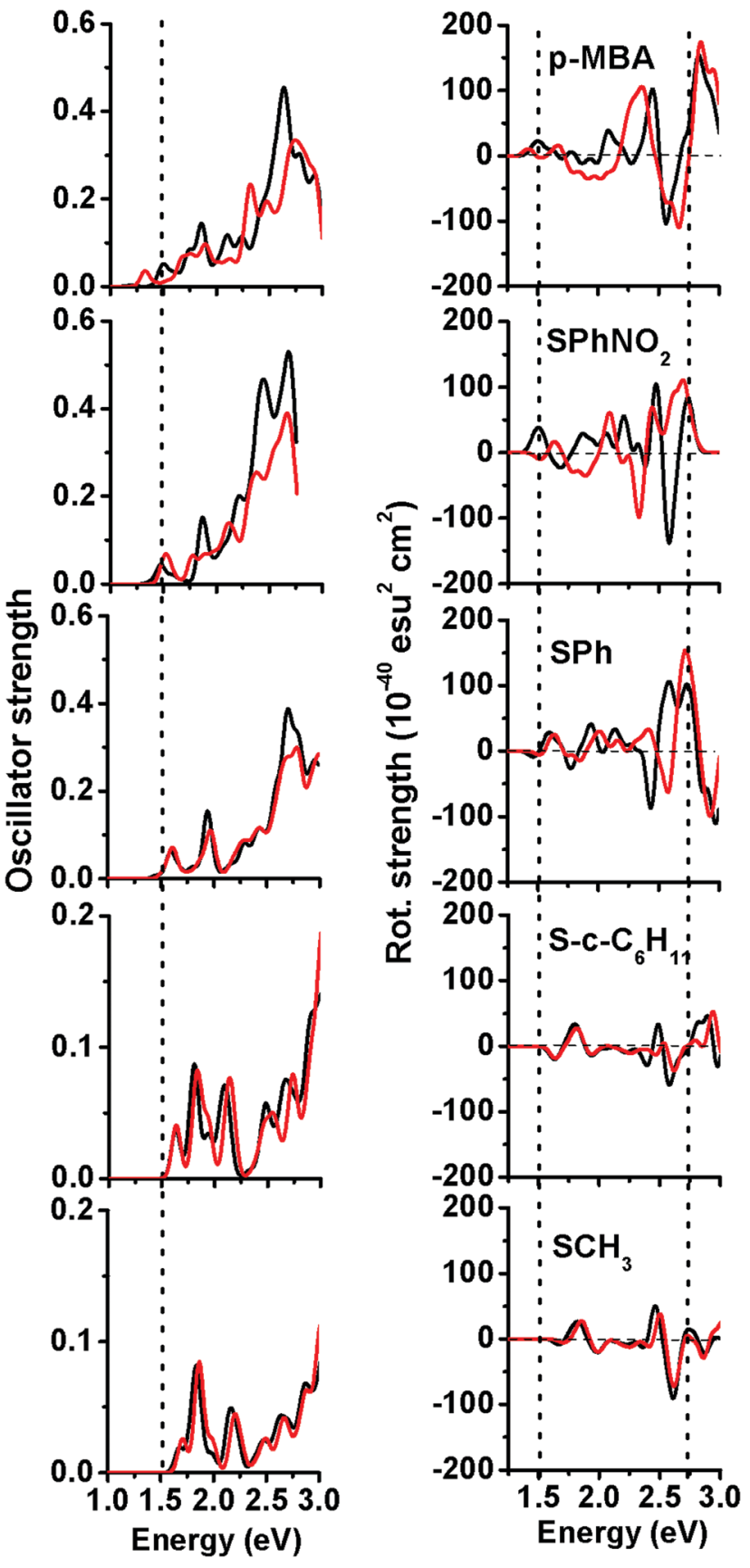

Fig. 8 Calculated optical absorption and CD spectra of clusters protected by achiral ligands. Black curves correspond with DFT calculations, while red ones show DFT-D calculations. There is remarkable difference in intensities between both kinds of calculations for $\mathrm{SPhNO}_{2}$ and $p-\mathrm{MBA}$ ligands. The intensity of UV and CD peaks is enhanced by a factor of approx. three for clusters protected by $\mathrm{SPhNO}_{2}$ and $p-\mathrm{MBA}$ ligands. Dotted lines in the UV spectra indicate the major shift toward lower energies undergo by $p$-MBA cluster based on DFT-D calculations. The second dotted line in the $C D$ spectra indicates a common negative peak found in all DFT calculations. A Gaussian broadening of $0.1 \mathrm{eV}$ has been used for both kinds of spectra.

with $61 \%$ contribution from $\mathrm{O}$ atoms, $24 \%$ contribution from $\mathrm{C}$ atoms, and $7 \%$ contribution from $\mathrm{S}$ atoms, respectively. The peak located at $1.99 \mathrm{eV}$ is due to HOMO $\rightarrow \mathrm{L}+2(84 \%)$, and 
$\mathrm{H}-14 \rightarrow$ LUMO (5\%) electronic transitions. Also, a first $1.19 \mathrm{eV}$ electronic transition with a small oscillator strength, involves to HOMO and LUMO (99\%) levels.

In general, the UV spectra of clusters including $\mathrm{SPhNO}_{2}$ $(\mathrm{H}-4 \rightarrow \mathrm{L}+11$ (20\%), H-7 $\rightarrow$ L+6 (12\%), H-5 $\rightarrow$ L+10 (12\%)), $\mathrm{SPh}(\mathrm{H}-2 \rightarrow \mathrm{L}+5$ (24\%), H-7 $\rightarrow \mathrm{L}+3$ (23\%), H-4 $\rightarrow \mathrm{L}+4(13 \%))$ and $p$-MBA ( $\mathrm{H}-9 \rightarrow \mathrm{L}+3$ (46\%), $\mathrm{H}-10 \rightarrow \mathrm{L}+3$ (22\%), $\mathrm{H}-23 \rightarrow$ L+1 (10\%)) ligands display an intense peak located circa $2.75 \mathrm{eV}$ which is missing for clusters protected with no aromatic rings. Those peaks can be attributed to levels with an important contribution from $\mathrm{Au}$ and $\mathrm{S}$ atoms.

The cluster including $\mathrm{SCH}_{3}$ as a ligand is unique, which exhibits similar CD signals based on both DFT and DFT-D calculations. In contrast, including $\mathrm{S}-c-\mathrm{C}_{6} \mathrm{H}_{11}$ as protecting ligands and based on both kinds of calculations result in slightly different profiles in the range from 2.25 to $2.80 \mathrm{eV}$ approx. (Fig. S11, ESI $\dagger$ ). The CD spectra of other compounds show an evident major difference. It has been verified that there is a slight shift toward lower energies of CD curves for the more distorted $p$-MBA protected cluster, and this result is in line with a previous study on the thiolated $\mathrm{Au}_{25}$ cluster. ${ }^{9}$ A negative peak located at $2.61 \mathrm{eV}$ is common to all relaxed clusters based on DFT calculations.

Turning our attention back to the second set of three chiral ligands, constituted by $\mathrm{S}-\mathrm{CH}_{2}-\mathrm{CH}\left(\mathrm{CH}_{3}\right)-\mathrm{Ph}, \mathrm{S}-\mathrm{CH}_{2}-\mathrm{CH}\left(\mathrm{NH}_{2}\right)-$ $\mathrm{Ph}$ (2-PET- $\left.\mathrm{NH}_{2}\right),{ }^{26}$ and L-cysteine, ${ }^{25}$ the effect of $\mathrm{SCH}_{3}$ and 2-PET ligands on the UV spectra is depicted in Fig. S12 (ESI $\dagger$ ), where 2-PET holds a slightly more intense profile, but both profiles look quite similar. The presence of a phenyl ring on the 2-PET ligand does not have a strong effect on its obtained UV spectrum, and this can be ascribed to the distant location of phenyl rings from the gold core. In contrast, the achiral SPh ligand holds a more intense profile when compared to the $\mathrm{Au}_{18}$ cluster protected by chiral 2-PET-Met ligands (Fig. S13, ESI $\dagger$ ) and this effect may be attributed to its proximity to the gold core.

Interestingly the displayed bonding types of 2-PET and 2-PET-Met structures (Fig. S14, ESI $\dagger$ ) are similar and their optical absorption spectra are closely related. Specifically, for those structures where no active groups form part of the ligands, the optical properties seem to be independent of the chirality of the ligand. On the other hand, the cluster protected by $p$-MBA shows a stronger optical absorption spectrum when compared to achiral MPA ligands which do not include phenyl rings (Fig. S15, ESI $\dagger$ ). From these results, it seems straightforward to conclude that the presence of phenyl rings, which are close to the gold core, results in a strong UV spectrum and it is not related to the chirality of the ligand (see Fig. S13, $\mathrm{ESI} \dagger$, where $\mathrm{Au}_{18}$ protected by achiral SPh ligands exhibits a more intense UV spectrum). Regarding the studied chiral ligands, it is important to mention that L-cysteine can be considered as a realistic one (Fig. 9). It is found that its UV spectrum features an intense first peak due mostly to HOMO to LUMO transitions (contribution of $68 \%$ ). Its intensity is even larger than the peak depicted by SPh ligands. Given the fact that L-cysteine does not have phenyl rings, the enhanced first peak must be related to other effects. The displayed bonding shows similar $\mathrm{O}-\mathrm{H}, \mathrm{N}-\mathrm{H}$ and $\mathrm{C}-\mathrm{H}$ bonds (Fig. 7); another fact is that $\mathrm{L}$-cysteine induces a strong distortion of the $\mathrm{Au}-\mathrm{S}$ framework as

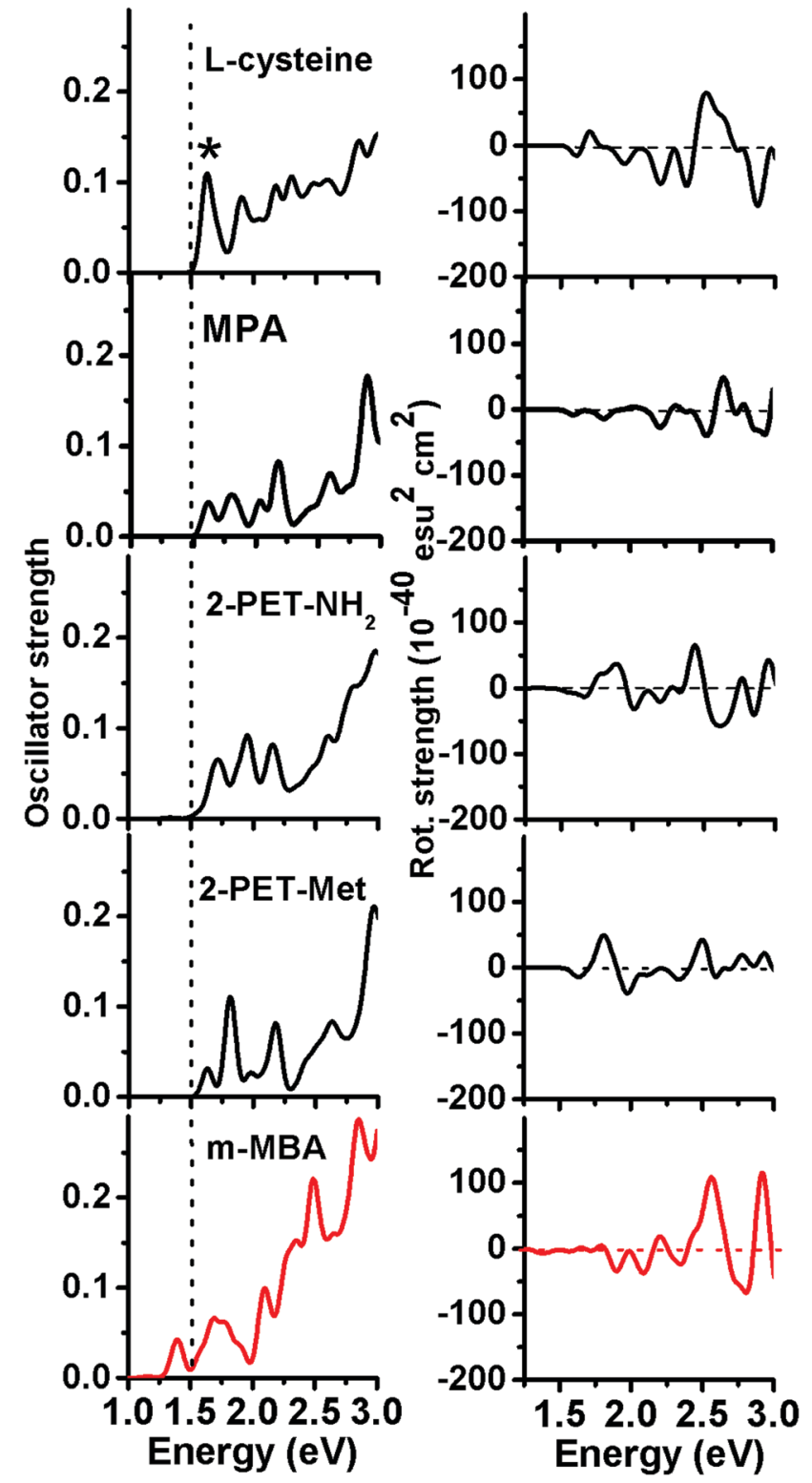

Fig. 9 Calculated optical absorption and CD spectra of clusters protected by chiral ligands, except MPA and $m$-MBA. Black and red curves correspond with DFT and DFT-D calculations, respectively. Dotted lines in the UV spectra indicate the major shift toward lower energies undergo by $m$-MBA cluster. The CD spectra feature a common positive peak found for clusters protected by achiral $m$-MBA and chiral L-cysteine ligands. Clearly more intense UV and CD peaks are featured by cluster protected by achiral $m$-MBA ligand. Asterisk indicates an enhanced first peak of cluster protected by L-cysteine. A Gaussian broadening of $0.1 \mathrm{eV}$ has been used for both kinds of spectra.

MPA does. The contribution to the energy levels (Fig. S16, ESI $\dagger$ ) demonstrates that oxygen atoms contribute to those levels up to the HOMO level in such a manner that the presence of oxygen atoms has a strong effect on the electronic structure of the $\mathrm{Au}_{18}$ cluster protected by L-cysteine.

On the other hand, achiral $m$-MBA ligands ${ }^{27}$ feature visible differences on CD and UV profiles with respect to achiral $p$-MBA ligands (Fig. 8 against Fig. 9). 
In general, the enhancement on the CD and UV spectra is related to the presence of oxygen atoms, phenyl rings, or a similarity of bonds as mentioned in the structure protected by L-cysteine. It is noteworthy that a trend cannot be established based only on the chirality of the studied ligands.

\section{Conclusions}

A study of the effect of ligands on the optical and chiroptical properties of the thiolated $\mathrm{Au}_{18}$ cluster was carried out based on DFT and DFT-D calculations. Clearly, $\mathrm{Au}_{18}$ clusters protected by achiral ligands such as $p$-MBA, SPh ligands, and $m$-MBA or protected by chiral L-cysteine ligands show a major distortion in their $\mathrm{Au}-\mathrm{S}$ framework and on their inner gold core. This distortion seems to be not related to the chirality of the ligand, i.e. the distortion induced by chiral $\mathrm{S}-\mathrm{CH}_{2}-\mathrm{CH}\left(\mathrm{CH}_{3}\right)-\mathrm{Ph}$ ligands is similar to the influence of achiral 2-PET ligands.

Moreover, the major distortion can be related to the presence of active groups (containing oxygen) and to their interligand interactions, or it can be ascribed to the presence of phenyl rings which are located close to the gold core.

The ligand effect on thiolated $\mathrm{Au}_{18}$ clusters is reflected in the bonding, electronic, optical and chiroptical properties, and the contribution to the energy levels from oxygen atoms in the $p$-achiral MBA, $m$-MBA, and chiral L-cysteine protected clusters is high. Conversely, $\mathrm{SCH}_{3}$ and $\mathrm{S}-\mathrm{c}-\mathrm{C}_{6} \mathrm{H}_{11}$ ligands depict a similarity in their bonding, UV and $\mathrm{CD}$ spectra, and therefore S- $c-\mathrm{C}_{6} \mathrm{H}_{11}$ ligands (involved during experiments) can be simplified by $\mathrm{SCH}_{3}$ ligands during calculations.

On the other hand, it was found that $\mathrm{Au}_{18}$ clusters protected by achiral ligands such as $\mathrm{SPh}$ show a slightly more intense UV profile than chiral $\mathrm{S}-\mathrm{CH}_{2}-\mathrm{CH}\left(\mathrm{CH}_{3}\right)-\mathrm{Ph}$ ligands in such a manner that chiral ligands (i.e. 2-PET-Me and 2-PET- $\mathrm{NH}_{2}$ ) may not induce stronger CD or UV signals. This result is in accordance with a study carried out on thiolated $\mathrm{Au}_{38}$ clusters, where chiral BINAS ligands were not able to induce a strong CD signal. ${ }^{28}$

Finally, our study supports the idea that active groups and phenyl rings close to the gold core have a strong effect on the structural, electronic and chiroptical properties. In this sense, our results provide new insight into the knowledge of the ligand effect on thiolated gold clusters. ${ }^{8,9}$ In order to gain more insight into the chirality of these compounds, please read the work by Prof. Bürgi and references included in ref. 29.

\section{Acknowledgements}

The author acknowledges the financial support provided through the grants: PRODEP DSA/103.5/15/6797, and PAICYT 2015; the author thankfully acknowledges the computer resources, technical expertise and support provided by the Laboratorio Nacional de Supercómputo del Sureste de México.

\section{Notes and references}

1 (a) S. Chen, S. Wang, J. Zhong, Y. Song, J. Zhang, H. Sheng, Y. Pei and M. Zhu, Angew. Chem., Int. Ed., 2015, 54,
3145-3149; (b) A. Das, C. Liu, H. Y. Byun, K. Nobusada, S. Zhao, N. Rosi and R. Jin, Angew. Chem., 2015, 127, 3183-3187. 2 (a) A. Tlahuice and I. L. Garzón, Phys. Chem. Chem. Phys., 2012, 14, 3737-3740; (b) A. Tlahuice and I. L. Garzón, Phys. Chem. Chem. Phys., 2012, 14, 7321-7329.

3 T. Tsukuda, H. Tsunoyama and Y. Negishi, in Metal Nanoclusters in Catalysis and Materials Science: The Issue of Size Control, ed. B. Corain, G. Schmid and M. Toshima, Elsevier, Amsterdam, 2008, p. 373.

4 B. Molina and A. Tlahuice-Flores, Phys. Chem. Chem. Phys., 2016, 18, 1397-1403.

5 (a) A. Ghosh, T. Udayabhaskararao and T. Pradeep, J. Phys. Chem. Lett., 2012, 3, 1997-2002; (b) K. G. Stamplecoskie and P. V. Kamat, J. Am. Chem. Soc., 2014, 136, 11093-11099.

6 (a) P. Hohenberg and W. Kohn, Phys. Rev., 1964, 136, B864-B871; (b) W. Kohn and L. J. Sham, Phys. Rev., 1965, 140(4A), A1133-A1138.

7 S. Grimme, J. Comput. Chem., 2006, 27, 1787-1799.

8 A. Tlahuice-Flores, M. Jose-Yacamán and R. L. Whetten, Phys. Chem. Chem. Phys., 2013, 15, 19557-19560.

9 A. Tlahuice-Flores, R. L. Whetten and M. Jose-Yacaman, J. Phys. Chem. C, 2013, 117, 20867-20875.

10 (a) A. Das, T. Li, G. Li, K. Nobusada, C. Zeng, N. L. Rosi and R. Jin, Nanoscale, 2014, 6, 6458-6462; (b) Y. Song, S. Wang, J. Zhang, X. Kang, S. Chen, P. Li, H. Sheng and M. Zhu, J. Am. Chem. Soc., 2014, 136, 2963-2965; (c) Y. Pei, R. Pal, C. Liu, Y. Gao, Z. Zhang and X. C. Zeng, J. Am. Chem. Soc., 2012, 134, 3015-3024.

11 S. Malola, L. Lehtovaara, S. Knoppe, K.-J. Hu, R. E. Palmer, T. Buurgi and H. Hakkinen, J. Am. Chem. Soc., 2012, 134, 19560-19563.

12 C. Zeng, Y. Chen, C. Liu, K. Nobusada, N. L. Rosi and R. Jin, Sci. Adv., 2015, 1, e1500425.

13 (a) P. R. Nimmala and A. Dass, J. Am. Chem. Soc., 2011, 133, 9175-9177; (b) C. Zeng, H. Qian, T. Li, G. Li, N. L. Rosi, B. Yoon, R. N. Barnett, R. L. Whetten, U. Landman and R. Jin, Angew. Chem., Int. Ed., 2012, 51, 13114-13118; (c) A. Das, C. Liu, C. Zeng, G. Li, T. Li, N. L. Rosi and R. Jin, J. Phys. Chem. A, 2014, 118, 8264-8269.

14 (a) J. P. Perdew, J. A. Chevary, S. H. Vosko, K. A. Jackson, M. R. Pederson, D. J. Singh and C. Fiolhais, Phys. Rev. B: Condens. Matter Mater. Phys., 1992, 46, 6671-6687; (b) A. D. Becke, Phys. Rev. A: At., Mol., Opt. Phys., 1998, 38, 3098-3100.

15 P. Perdew, K. Burke and M. Ernzerhof, Phys. Rev. Lett., 1996, 77, 3865-3868.

16 M. J. Frisch, G. W. Trucks, H. B. Schlegel, G. E. Scuseria, M. A. Robb, J. R. Cheeseman, G. Scalmani, V. Barone, B. Mennucci, G. A. Petersson, H. Nakatsuji, M. Caricato, X. Li, H. P. Hratchian, A. F. Izmaylov, J. Bloino, G. Zheng, J. L. Sonnenberg, M. Hada, M. Ehara, K. Toyota, R. Fukuda, J. Hasegawa, M. Ishida, T. Nakajima, Y. Honda, O. Kitao, H. Nakai, T. Vreven, J. A. Montgomery, Jr., J. E. Peralta, F. Ogliaro, M. Bearpark, J. J. Heyd, E. Brothers, K. N. Kudin, V. N. Staroverov, T. Keith, R. Kobayashi, J. Normand, K. Raghavachari, A. Rendell, J. C. Burant, S. S. Iyengar, J. Tomasi, M. Cossi, N. Rega, J. M. Millam, M. Klene, 
J. E. Knox, J. B. Cross, V. Bakken, C. Adamo, J. Jaramillo, R. Gomperts, R. E. Stratmann, O. Yazyev, A. J. Austin, R. Cammi, C. Pomelli, J. W. Ochterski, R. L. Martin, K. Morokuma, V. G. Zakrzewski, G. A. Voth, P. Salvador, J. J. Dannenberg, S. Dapprich, A. D. Daniels, O. Farkas, J. B. Foresman, J. V. Ortiz, J. Cioslowski and D. J. Fox, Gaussian 09, Revision D.01, Gaussian, Inc., Wallingford CT, 2013.

17 P. D. Jadzinsky, G. Calero, C. J. Ackerson, D. A. Bushnell and R. D. Kornberg, Science, 2007, 318, 430-433.

18 G. Li, C. Zeng and R. Jin, J. Am. Chem. Soc., 2014, 136, 3673-3679.

19 M. Rambukwella, L. Sementa, G. Barcaro, A. Fortunelli and A. Dass, J. Phys. Chem. C, 2015, 119, 25077-25084.

20 A. Das, T. Li, K. Nobusada, C. Zeng, N. L. Rosi and R. Jin, J. Am. Chem. Soc., 2013, 135, 18264-18267.

21 L. Sementa, G. Barcaro, A. Dass, M. Stener and A. Fortunelli, Chem. Commun., 2015, 51, 7935-7938.
22 C. Zeng, Y. Chen, G. Li and R. Jin, Chem. Mater., 2014, 26, 2635-2641.

23 M. O. Sinnokrot and C. D. Sherrill, J. Phys. Chem. A, 2004, 108, 10200-10207.

24 M. W. Heaven, A. Dass, P. S. White, K. M. Holt and R. W. Murray, J. Am. Chem. Soc., 2008, 130, 3754-3755.

25 C.-C. Huanga and H.-T. Chang, Chem. Commun., 2007, 1215-1217.

26 T. Cao, S. Jin, S. Wang, D. Zhang, X. Meng and M. Zhu, Nanoscale, 2013, 5, 7589-7595.

27 M. Azubel, J. Koivisto, S. Malola, D. Bushnell, G. L. Hura, A. L. Koh, H. Tsunoyama, T. Tsukuda, M. Petterson, H. Hakkinen and R. D. Kornberg, Science, 2014, 22, 909-912.

28 B. Molina, A. Sánchez-Castillo, S. Knoppe, I. L. Garzón, T. Bürgi and A. Tlahuice-Flores, Nanoscale, 2013, 5, 10956-10962.

29 S. Knoppe and T. Bürgi, Acc. Chem. Res., 2014, 47, 1318-1326. 